\title{
Anti Inflammatory Effect of Azadirachta Indica (Neem) In Albino Rats-An Experimental Study
}

\author{
${ }^{1}$ Dr. Jagadeesh. K, ${ }^{2}$ Dr. Srinivas. K, ${ }^{* 1}$ Dr. Shreenivas. P. Revankar. \\ 1. Department of Pharmacology; Shimoga Institute of Medical Sciences; Shimoga-577201, Karnataka. \\ 2. Associate Professor Department of Pharmacology; DM Wayanad Institute of Medical \\ Sciences.Naseeranagar; Meppadi, Wayanad, Kerala-673577
}

\begin{abstract}
:
Introduction: Inflammation is body's attempt at self protection characterized by five cardinal signs; it may be acute or chronic. NSAID(non steroidal anti-inflammatory drugs are the commonly used to reduce the inflammation. traditional Indian system of medicine mentions neem(Azadirachta Indica)to have many medicinal properties. so the present study was carried out to access the anti-inflammatory effect of neem.

Materials and methods: Albino rats were used; they were divided into three groups. Control group treated with normal saline, standard treated with Indomethacin and test drug used was neem oil. For acute inflammation; Carregennan induced rat paw edema inhibition method and for sub acute inflammation: cotton pellet granulation method. Ulcer index of Indomethacin and test compound were also studied.

Results: it is found that neem oil showed significant anti-inflammatory effect in both acute as well as chronic inflammation, it was also found to have low ulcerogenic potential compared to Indomethacin, hence can be safely used as a potent anti-inflammatory agent
\end{abstract}

KEYWORDS: Neem (Azadirachta-Indica), Inflammation, Indomethacin, Carregennan, Cotton pellet

\section{INTRODUCTION:}

Inflammation is the body's attempt at self-protection; to remove harmful stimuli, damaged cells, irritants, or pathogens - and begin the healing process. The traditional names for signs of inflammation come from Latin: Dolor (pain),Calor (heat),Rubor (redness), Tumor (swelling), Functio laesa (loss of function). The first four (classical signs) were described by Celsus (ca. 30 BC-38 AD), while loss of function was added later by Galen. ${ }^{1}$ The process of acute inflammation is initiated by cells already present in all tissues, mainly resident macrophages, dendritic cells, histiocytes, Kupffer cells and mastocytes. ${ }^{1,2}$ Inflammation is of two types acute and chronic. Acute inflammation - starts rapidly (rapid onset) and quickly becomes severe. Signs and symptoms are only present for a few days, but in some cases may persist for a few weeks. Examples: acute bronchitis, infected ingrown toenail, sore throat from a cold or flu, a scratch/cut on the skin, exercise (especially intense training), acute appendicitis, acute dermatitis, acute tonsillitis, acute infective meningitis, acute sinusitis, or a blow. ${ }^{2,3}$ Chronic inflammation - last for several months and even years. The important causes are an autoimmune response to a self antigen. A chronic irritant of low intensity that persists. Examples of diseases and conditions with chronic inflammation include: asthma, chronic peptic ulcer, tuberculosis, rheumatoid arthritis, chronic periodontitis, ulcerative colitis and Crohn's disease, chronic sinusitis, and chronic active hepatitis. ${ }^{3,4}$ The drugs that reduce the inflammatory process are called as antiinflammatory drugs.NSAID (non steroidal anti-inflammatory drugs) is the most commonly used antiinflammatory drugs. They mainly bring about the action by inhibiting the (COX) cycloxygenase enzyme. ${ }^{5}$

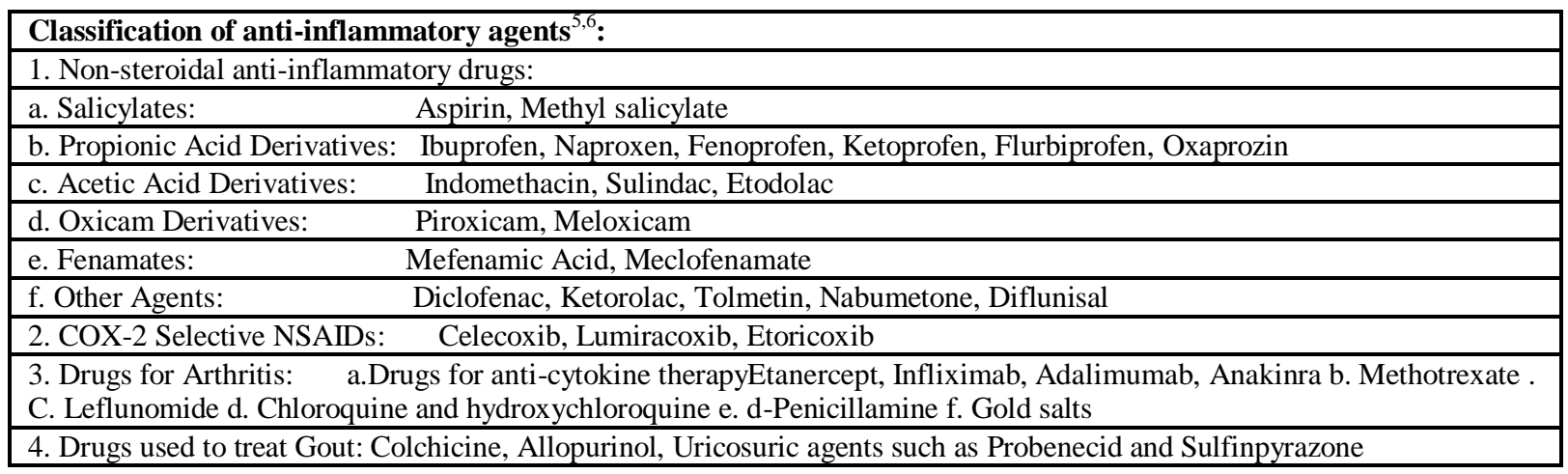


NSAIDs aside from aspirin, both newer selective COX-2 inhibitors and traditional anti-inflammatory agents, increase the risk of myocardial infarction and stroke. ${ }^{7}$ In people with heart failure,

NSAIDs increase mortality risk by approximately 1.2-1.3 for naproxen and ibuprofen, 1.7 for rofecoxib and celecoxib, and 2.1 for diclofenac.A 2005 study linked long term (over 3 months) use of NSAIDs, including ibuprofen, with a 1.4 times $(140 \%)$ increased risk of erectile dysfunction.NSAIDs cause a dual assault on the GI tract: the acidic molecules directly irritate the gastric mucosa, and inhibition of COX-1 and COX-2 reduces the levelsof protective prostaglandins.CommongastrointestinalADRsinclude: ${ }^{[9]}$.Nausea/Vomiting,Dyspepsia,Gastric ulceration/bleeding, diarrhea. ${ }^{7}$ Azadirachta Indica, commonly known as neem, has attracted worldwide prominence in recent years, owing to its wide range of medicinal properties. Neem has been extensively used in Ayurvedic, Unani and Homoeopathic medicine and has become a cynosure of modern Medicine. ${ }^{8}$ All parts of the neem tree- leaves, flowers, seeds, fruits, roots and bark have been used traditionally for the treatment of inflammation, infections, fever, skin diseases and dental disorders. ${ }^{8,9}$ The medicinal utilities have been described especially for neem leaf. Neem leaf and its constituents have anti-inflammatory, antihyperglycaemic, antiantioxidant, antimutagenic and anticarcinogenic properties ${ }^{10}$. So the present study was taken up to explore the anti-inflammatory properties in albino rats.

\section{MATERIALS AND METHODS:}

Chemicals: carragennan, carboxy methyl cellulose, Indomethacin, gum acacia, neem oil and ether. Equipments: plethysmograph,ryles(infant feeding)tube, wooden mouth gag,syringes,dissection set, skin suturing set, magnifying lens, mortar and pestle, sterile cotton pellets and grass pith, Gum acacia: is used as vehicle for the administration of indomethacin.the drug are administered orally, through the infant feeding tube, as fine suspension in 5\% gum acacia. Ether: is used to anaesthise the rats during implantation and removal of cotton pellets and while sacrificing the rats for postmortem examination. Indomethacin: has a prominent antiinflammatory, analgesic and antipyretic property similar to those of salicylates. ${ }^{5} \mathrm{Neem}$ : is found to exert an analgesic and anti-inflammatory activity ${ }^{11}$ in the albino rats. The test material showed significant antiinflammatory effect against 5HT and PGE1 induced inflammation. ${ }^{9}$ Though the exact mechanism is not known, there is always scope for further studies. Albino rats weighing 100 to $200 \mathrm{gms}$ between 21 days to 4 months of age, with no visible disease.

\section{METHODS:}

For acute inflammation: carragennan induced rat paw edema inhibition method. For subacute inflammation: cotton pellet granulation method.

Carragennan induced rat paw edema inhibition method ${ }^{12,13}$ : wistar albino rats were divided into 3 groups each containing 6 rats. Inflammation was produced by injecting $0.1 \mathrm{ml}$ of carregennan suspension in normal saline to right hand paw. One hour after drug administration, $0.1 \mathrm{ml}$ of $1 \%$ carregennan in 0.5 carboxymethy cellulose was injected into the sub plantar region of one of the hind paws.a mark was made on the leg at the malleous to facilitate uniform dipping at subsequent readings. The paw edema volume was measured with the help of plethysmograph by mercury displacement method at zero hour (immediately after injecting carregennan). The same procedure was repeated at $1,2,3 \& 4$ hours. The percentage inhibition of oedema in various treated groups was then calculated by using the formula.

First group: control group receiving no drug

Second group: standard control was administered Indomethacin in a dose of $20 \mathrm{mg} / \mathrm{kg}$ body weight.

Third group: was given the test compound in the dose of 1,2,4,8ml/kg bodyweight intraperitonially 1 hour prior to carragennan injection.paw volumes will be measured using plethysmograph in each group at 0 and 3 hours after carregennan injection.

$\%$ edema inhibition $=\mathrm{Vc}-\mathrm{Vt} / \mathrm{Vc} \times 100$

Where $\mathrm{Vt}$-is the mean edema volume in the drug treated group

$\mathrm{Vc}$-is the mean edema volume in control group.

Plethysmograph $^{12}$ : fabrication of this instrument consists of vertical glass cylinder A which is $8 \mathrm{cms}$ in length and $14 \mathrm{~mm}$ inside diameter. This cylinder is attached to another glass tube B of $3 \mathrm{~mm}$ diameter by means of a glass tube which is horizontal in position. This system enables mercury to stand at nearly same levels. The diameter of the horizontal connecting glass tube is same as that of inside tube $\mathrm{B}$, the cylinder A Is also connected with the graduated pipette by means of another connecting glass tube of $3 \mathrm{~mm}$ diameter. The pipettes capacity is $2 \mathrm{ml}$ and divided into 200 divisions. The zero mark is so adjusted that mercury in these three vertical glass cylinders and side tubes stand at same level. The upper end of the pipette is connected to an $\mathrm{H}$ shaped stopper. The upper way has got a stopper SI and the side limb is connected to a syringe interfered by another stopperS2.after putting mercury upto the levels should be so adjusted that they lie at the same horizontal line. 
The zero on the pipette corresponds to the level of mercury in it, at the initial setting. Operation of the apparatus: at the beginning the mercury level was adjusted to zero mark by the help of syringe X, stopper S1 was closed and S2 was kept open.

The hind paw of the rat was made to dip in the mercury of cylinder A. as a result the levels of mercury go little higher in all the tubes as well as in cylinder A .keeping the paw inside the cylinder the level of mercury was brought down to the initial level by drawing the piston of syringe $\mathrm{X}$. This results in elevation of mercury level I the pipette and lowering of mercury levels in the cylinder A and tube B. After the levels in the cylinder A and side tube B were brought to initial levels the stopper S2 was closed and the paw was taken out of cylinder A. Elevated mercury from zero in the pipette gives the volume of the paw. This procedure needs two operators; one to dip the rat paw and other to adjust the mercury levels. The whole apparatus was supported with the help of a fixing stand $\mathrm{Z}$ during the procedure. Cotton pellet granuloma method ${ }^{14,15}$ : rats were divided into 5 groups consisting 6 rats. Under light ether anesthesia the hair in the axillary and groin region were cut and sterile cotton pellets of $15 \mathrm{mg}$ each were implanted in the subcutaneous tissue on either sides of axilla and sterile grass pith $(25 \times 2 \mathrm{~mm})$ in the groin region. Wounds were then sutured and animals were caged individually after recovery from anesthesia. The rats then received treatments as described. The schedule of drug administration was started on the day of implantation and repeated every 24 hours, regularly for 7 days, any change in food intake, motor activity and diarrhea if any were noted. On the $8^{\text {th }}$ day, the rats were sacrificed and cotton pellets and grass pith removed. The pellets freed from tissue, were dried overnight at $60 \mathrm{C}$ to their dry weight. Net granuloma weight was calculated by subtracting initial weight of cotton pellet $(15 \mathrm{mg})$ from weight noted. The grass pith was served in $10 \%$ formalin for histopathological studies. Percentage of granuloma inhibition in various treated groups was calculated using the formula;

$\%$ inhibition $=\mathrm{Wc}-\mathrm{Wt} / \mathrm{Wc} \times 100$ where

Wc-mean dry weight of pellet granuloma for control group

Wt- mean dry weight of pellet granuloma of test group.

Stomachs were cut open along the greater curvature and washed with normal saline. Gastric mucosa was examined for the erosions, hemorrhagic spots, ulcers and perforations, if any with the help of magnifying glass. To determine the severity of the ulcers arbitrary scoring system as described by Gupta M B etal, 1985 was followed.

a) Denuded epithelium==10 b) petechial and frank hemorrhages=20; one or two ulcers $=30$; multiple ulcers $=40$; perforated ulcers $=50$

IV. RESULTS:

Table -1 : CARRAGENNAN INDOCED RAT PAW OEDEMA INHIBITION TEST

\begin{tabular}{|c|c|c|c|c|c|c|}
\hline Group & & & Test col & & & \\
\hline Rats & Control & Indomethacin & $\mathrm{A}=\mathrm{IML}$ & $\mathrm{B}=2 \mathrm{ML}$ & $\mathrm{C}=4 \mathrm{ml}$ & $\mathrm{D}=\mathrm{SML}$ \\
\hline 1 & 0.3 & 0.1 & 0.1 & 0.2 & 0.1 & 0.1 \\
\hline 2 & 0.4 & 0.2 & 0.3 & 0.1 & 0.2 & 0.3 \\
\hline 3 & 0.3 & 0.1 & 0.2 & 0.3 & 0.1 & 0.1 \\
\hline 4 & 0.4 & 0.2 & 0.3 & 0.4 & 0.2 & 0.2 \\
\hline 5 & 0.4 & 0.3 & 0.2 & 0.1 & 0.3 & 0.1 \\
\hline 6 & 0.3 & 0.1 & 0.1 & 0.2 & 0.2 & 0.1 \\
\hline Mean & 0.37 & 0.17 & 0.20 & 0.22 & 0.18 & 0.19 \\
\hline SD & 0.08 & 0.08 & 0.09 & 0.12 & 0.08 & 0.08 \\
\hline$\overline{\mathrm{SE}}$ & 00.3 & 0.03 & 0.04 & 0.05 & 0.03 & 0.03 \\
\hline P-Value & & $<01$ & $<05$ & $\mathrm{NS}$ & $<01$ & $<05$ \\
\hline $\begin{array}{l}\% \text { oedema } \\
\text { inhibition }\end{array}$ & & 54.5 & 45.5 & 40.9 & 50.0 & 48.2 \\
\hline
\end{tabular}

ANOVA, $\mathrm{F}=4.39, \mathrm{P}<.01$, significant,

Studentized range test: LSD: $\quad 0.16$ P.05

$0.19 \mathrm{P}<.01$

SD: Standards deviation, SE: standard error

$\%$ edema inhibition $=\mathrm{Vc}-\mathrm{Vt}$ X $100 / \mathrm{Vc}$

Where, Vc : Mean oedema volume for the control group.

$\mathrm{Vt}$ : Mean oedema volume for the test group 
Dosages: Indomethamacin $20 \mathrm{mg} / \mathrm{kg}$ b.w.

Text compounds $\mathrm{A}=1 \mathrm{ml}, \mathrm{B}=2 \mathrm{ml}, \mathrm{C}=4 \mathrm{ml}, \mathrm{D}=8 \mathrm{ml}$.

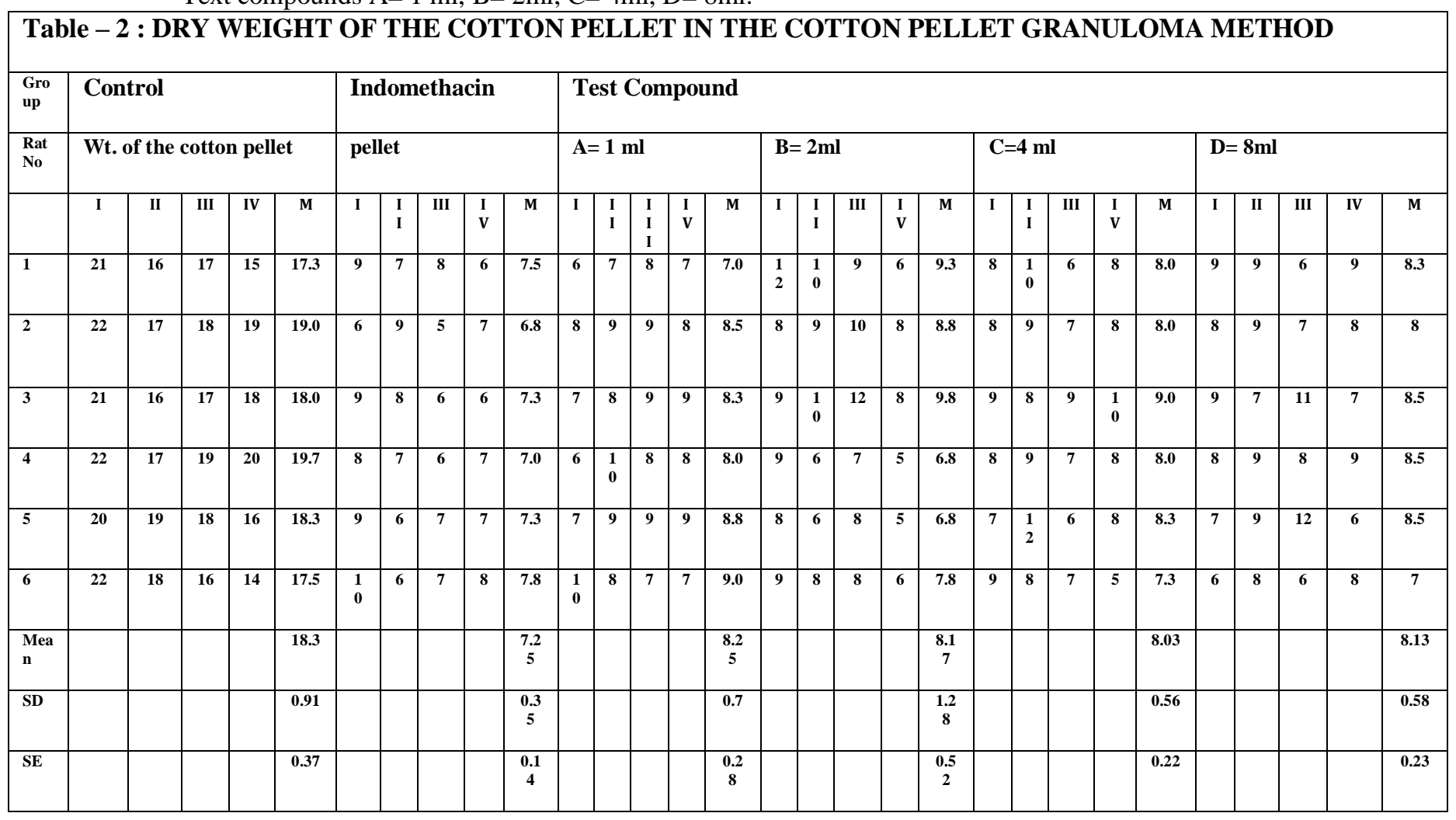

One way ANOVA, F=170.4, P<.001, Highly significant, SD: Standard deviation, SE: Standard error

$\mathrm{P}<.01$ when compared with control. No significant different between other groups
$\mathrm{LSD}=1.39$
$\mathrm{P}<.05$
$=1.70$
$\mathrm{P}<.01$

$\%$ Inhibition $=\mathrm{Wc}-\mathrm{Wt}$ X 100

Wc : Mean dry weight of the pellet granuloma for the control group. Wt : Mean dry weight of the pellet granuloma for the test group.

Table -3 : ULCER INDEX OF INDOMETHACIN AND TEST COMPUND

\begin{tabular}{|l|l|r|l|l|}
\hline Groups & \multicolumn{2}{|c|}{ Ulcer incidence } & \multicolumn{2}{c|}{ - value } \\
\hline & Rats with ulcer & \multicolumn{1}{l|}{$\%$} & With control & with Indomethacin \\
\hline Controls & $2 / 6$ & 33.3 & & $<0.05$ \\
\hline Indomethacin & $6 / 6$ & 100 & $<0.05, \mathrm{~S}$ & \\
\hline Test compound A & $3 / 6$ & 50 & NS & NS \\
\hline B & $3 / 6$ & 50 & NS & NS \\
\hline C & $4 / 6$ & 66.7 & NS & NS \\
\hline D & $4 / 6$ & 66.7 & NS & NS \\
\hline
\end{tabular}

Fischer's exact test

$\mathrm{P}<0.05$ Significant

$\mathrm{P}>0.05$ Non significant

Dosage : Indomethacin $20 \mathrm{mg} / \mathrm{kg}$ b.w

Text compounds $\mathrm{A}=1 \mathrm{ml} \mathrm{B}=2 \mathrm{ml}, \mathrm{C}=4 \mathrm{ml}, \mathrm{D}=8 \mathrm{ml}$ 


\section{DISCUSSION:}

It is evident from table 1 that the test compound in the following dosage $(1,2,4 \mathrm{ml})$ exhibit significant anti-inflammatory effect $(45.2 \%, 50 \%$ and $48.2 \%)$ very much comparable to that of control in carregennan induced rat paw edema inhibition test. This goes in accordance to the observation of Kumar etal. The activity of test compound in the dose of $2 \mathrm{ml} / \mathrm{kg}$ is not significant when compared to control.Table 2 indicates the chronic anti-inflammatory effect of the efficacy of test compound. It has got significant effect $(\mathrm{P}<0.01)$ when compared to the control. This goes in accordance to Rath Bhabegral et al.Table 3 shows the ulcerogenic effect of test compound was not significant .when compared to control the standard drug Indomethacin shows significant ulcerogenic effect when compared to test and control compound. Mechanism of action: the exact mechanism of action is still unclear. In the study by chattopadyaya et al showed that the test compound extract produces dose dependent inhibition of the inflammatory edema produced by 5HT and PGE, but its extract failed to suppress histamine and bradykinin induced edema. These observations support the conclusion that test compound has anti-inflammatory action probably by its anti 5HT and anti-PGE activity. Between the two edemogens A.indica exhibited greater action against PGE. Therefore A.indica resembles Indomethacin like drugs.

\section{REFERENCES:}

[1] Cotton RS ,Kumar V and Robbins S1. Robbins pathologic basis of disease. $5^{\text {th }}$ edn Philadelphia B Sauderers company ,1994.p.53-4

[2] Ritchie A C. Boyd's textbook of pathology, Canada, edn 9, USA; lea and feberger, 1990:p.60-88, 1044.

[3] Dey NC, Debashish S, Pey PK edn. Textbook of pathology; New central book agency ltd,19995:p.6.1-6.59

[4] Rubin E. Essential pathology, $2^{\text {nd }}$ edn, Chapter-2 inflammation, Philadelphia: Lippincort Williams \& Wilkins, 2001: p-24-46.

[5] Satoskar RS, Bhandarkar SD, Ainapur SS, Angiotensin, Kinins, Leukotrienes prostaglandins and cutokiones, $18^{\text {th }}$ edn. Bombay India; Popular Prakashan pvt. Ltd. 2003 p 333-9

[6] Tripathi KD. Essentials of medical pharmacology, $5^{\text {th }}$ edn $\cdot$ prostaglandin Leukotrienes, jaypee pub Pvt Ltd, 2004 P 156-166

[7] Regoli D and J. Barbe. Pharmacology of bradykinin and related Kinins. Pharmacol res. 1990; 32:1-146.

[8] Malbotra SC, Pharmacological investigations of certain medicinal plant used in Ayurveda and siddha. 1 st Edn. Central council for research in Ayurveda and sidda, New Delhi. 1996 : p 245

[9] Sanjay L, Bandana R, Shantilata O, Anti inflammatory activity of neem seed oil. Ind J pharmacol, 2000;33:303

[10] Williamson EM. Major herbs of ayurveda, $1^{\text {st }}$ Edn. Churchill livingstone, Newyork, 2002: p 56-63

[11] Chattopadhyay RR, Chattopadhyay RN, Maitra SK, Possible mechanism of anti-inflammatory activity of Azadrachta indica leaf extract, Ind J pharmacol, 1993; 25:99-100

[12] Winter CA, Risley ES, Noss GW. Carregennan induce oedema in hind paw of rat as assay for anti-inflammatory drugs. Proc soc exp bio med, 1962; 111:544-547.

[13] Turner R A. Screening methods in pharmacology, Newyork and London. Academic press inc., $1965 ;$ p.323.

[14] Bhabagrahi R, effect of neem lead extract (NLE) on cotton pellet granuloma in Albino rats. Ind J Pharmacol, 2002; 34: 297-8.

[15] Shubha R. A study of anti-inflammatory and analgesic property of newly synthesized 4-substituted coumarin derivative in albino rats. 